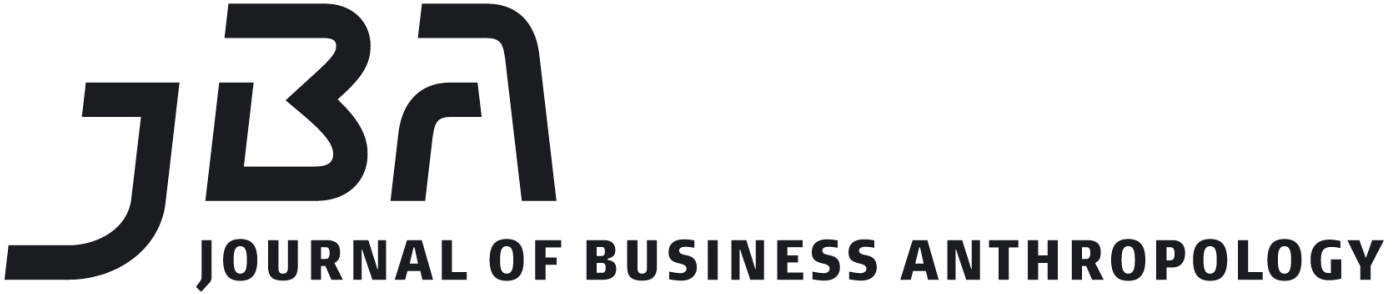

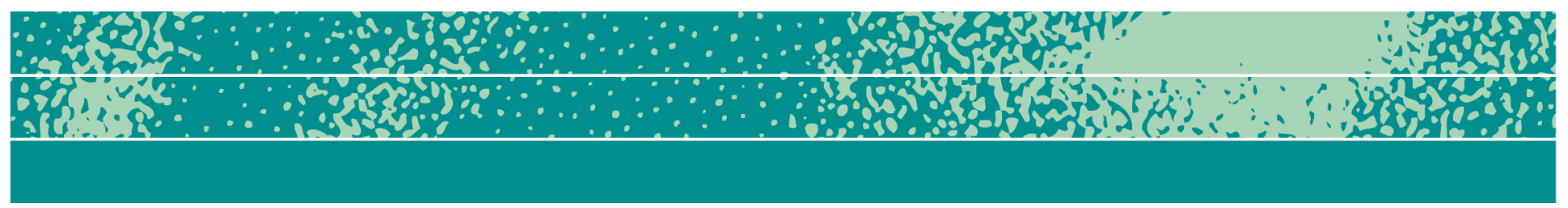

\section{The Behavioral Perspective on Pay What You Want Pricing*}

Ernest Baskin

PWYW pricing has always been non-normative from an economic perspective. As explained by Egbert (2017), it runs counter to neoclassical economic assumptions that consumers should behave rationally in seeking to maximize their own utility. Thus, the majority of people should pay zero for any product sold in a PWYW context. In concurring with the author that reciprocity plays a factor in influencing profitability in some PWYW pricing contexts, the economics and marketing literatures can add additional empirical evidence. Drawing on literature that showed how perceptions of fairness and altruism increased payments under PWYW pricing (Kim, Natter, and Spann 2009), Jung et al. (2014) showed that Pay-It-Forward pricing, where each consumer pays what they want for the purchase of the following consumer can increase revenue generated. In one of their studies, turning a museum's admissions prices from a PWYW pricing scheme to a scheme where each person paid what they wanted for the entrance fee of the next person in line increased entrance revenues for the museum. Thus, just by converting a short one off interaction into an ongoing reciprocity based situation, companies can increase the amount paid for their products. In those cases, reciprocity is occurring between individual consumers rather
Page 1 of 4

JBA 6(2): 231-234

Autumn 2017

(C) The Author(s) 2017

ISSN 2245-4217

www.cbs.dk/jba

* Comment on Egbert, Henrik, "Pay-What-You-Want Pricing," in this issue. 
than between consumers and the company providing the product. In addition, Pay-It-Forward has the added benefit over PWYW that the need to reciprocate is immediately highlighted and does not require paying attention to potential multiple future interactions between the company and its consumers.

However, other aspects of the PWYW environment must be taken into account in order to more fully understand when PWYW is most profitable for a company. For example, empirical evidence from Disney ride photo sales suggests that companies can earn more profit when PWYW is paired with a charitable donation (Gneezy et al. 2010). In their research, Gneezy et al. (2010) found that regular PYWY pricing decreased profitability as compared to fixed pricing while PWYW with 50\% going to charity increased it. In addition, Gneezy et al. (2012) found that diners in a restaurant in Vienna paid more for their food when they were paying the owner anonymously rather than directly. Both of these field studies suggest that self-perception concerns play a factor in PYWY profitability. The second study, in particular, shows how positive self perceptions may actually play a bigger role in determining profitability than the reciprocity motive as the anonymous payments did not reflect overt reciprocity but did give the purchaser a positive self-perception boost. This is consistent with the fact that people make many decisions in their lives based on the aspects these actions imply about themselves (Bodner and Prelec 2003). Importantly, positive self perceptions can be created in one off interactions for products and do not require the potential of multiple visits to create increased profitability for the company.

Finally, for a more complete understanding of the role of reciprocity in PYWY pricing, it is important to bring in the vast literature across psychology, marketing, consumer culture theory and other fields on gift-giving more generally and the mistakes we make regarding it. In particular, much of this literature suggests that, even though gift givers attempt to focus on the gift recipient, they are not always able to pick the best gift that the recipient will most enjoy. For instance, gift givers tend to err on the side of picking more desirable gifts while receivers prefer more usable gifts (Baskin et al. 2014). This is true even if norms are shared between the giver and the receiver such that the giver knows that, for example, their receiver prefers action video games over other types of gifts (including other video games). Givers also tend to believe that, the more money they spend on the gift, the more it will be appreciated, which is not the case (Flynn and Adams 2009). Similarly, givers tend to over individuate gifts when shopping for multiple recipients thus creating unique but worse gifts for their recipients (Steffel and LeBoeuf 2014). Even in gift giving situations where an explicit norm exists, such as wedding registries, gift givers, to their detriment, buy worse gifts by picking products not explicitly on the registry (Gino and Flynn 2011). These factors can affect the receiver's willingness to reciprocate and, 
potentially, the type of gift that they might be willing to give back.

Bringing this research back to the PWYW context, this makes it critically important for companies to consider how the product they are selling under the PWYW pricing scheme will be perceived by the buyer. Even though they might share similar value systems with their consumer, they might interpret the types of products that enhance reciprocity differently than their consumers will. For instance, Liu, Lamberton, and Haws (2015) found that firms commonly believe that small financial acknowledgments can express appreciation but consumers actually prefer verbal acknowledgements. Similarly, research on the presenter's paradox has shown that companies think that the more positive aspects they communicate about their products, the better consumers will perceive them. However, it turns out that consumers average all attributes and thus moderately positive attributes might detract from very positive attributes (Weaver, Garcia, and Schwarz 2012). When giving gifts, Baskin et al. (2014) suggest that practical products might work better in encouraging reciprocity than desirable products even though givers prefer to give desirable products. Thus, while attempting to ensure reciprocity improves PWYW payments, companies must keep in mind a variety of misperceptions and biases regarding their own products that they might be subject to with respect to their consumers.

Overall, the empirical literature does find support for reciprocity acting as an underlying cause of increased payments under PWYW pricing. However, it is important to remember that it is not the only cause and may not be the main driver of the price paid in certain situations.

Both the context and the type of product used in PYWY pricing scheme is critically important. Some contexts and some products work better than others even when taking potential reciprocity into account. The context in which PYWY is implemented is critically important, both in terms of how it makes the consumer feel and the type of product that is being sold under the PYWY pricing scheme.

\section{References}

Baskin, Ernest, Cheryl J Wakslak, Yaacov Trope, and Nathan Novemsky. 2014. "Why Feasibility Matters More to Gift Receivers than to Givers: A Construal-Level Approach to Gift Giving." Journal of Consumer Research 41 (1):169-182. https://doi.org/10.1086/675737

Bodner, Ronit, and Drazen Prelec. 2003. "Self-signaling in a neo-Calvinist model of everyday decision making." Psychology of economic decisions 1:105-126.

Flynn, Francis J., and Gabrielle S. Adams. 2009. "Money can't buy love: Asymmetric beliefs about gift price and feelings of appreciation." Journal 
of Experimental Social Psychology 45 (2):404-409.

https://doi.org/10.1016/j.jesp.2008.11.003

Gino, Francesca, and Francis J. Flynn. 2011. "Give them what they want: The benefits of explicitness in gift exchange." Journal of Experimental Social Psychology 47 (5):915-922. https://doi.org/10.1016/j.jesp.2011.03.015

Gneezy, Ayelet, Uri Gneezy, Leif D Nelson, and Amber Brown. 2010. "Shared social responsibility: A field experiment in pay-what-you-want pricing and charitable giving." Science 329 (5989):325-327. https://doi.org/10.1126/science.1186744

Gneezy, Ayelet, Uri Gneezy, Gerhard Riener, and Leif D Nelson. 2012. "Pay-what-you-want, identity, and self-signaling in markets." Proceedings of the National Academy of Sciences 109 (19):7236-7240. https://doi.org/10.1073/pnas.1120893109

Jung, Minah H, Leif D Nelson, Ayelet Gneezy, and Uri Gneezy. 2014. "Paying more when paying for others." Journal of personality and social psychology 107 (3):414-431. https://doi.org/10.1037/a0037345

Kim, Ju-Young, Martin Natter, and Martin Spann. 2009. "Pay what you want: A new participative pricing mechanism." Journal of Marketing 73 (1):44-58. https://doi.org/10.1509/jmkg.73.1.44

Liu, Peggy J, Cait Lamberton, and Kelly L Haws. 2015. "Should firms use small financial benefits to express appreciation to consumers? Understanding and avoiding trivialization effects." Journal of Marketing 79 (3):74-90. https://doi.org/10.1509/jm.14.0091

Steffel, Mary, and Robyn A LeBoeuf. 2014. "Overindividuation in gift giving: Shopping for multiple recipients leads givers to choose unique but less preferred gifts." Journal of Consumer Research 40 (6):1167-1180. https://doi.org/10.1086/674199

Weaver, Kimberlee, Stephen M Garcia, and Norbert Schwarz. 2012. "The presenter's paradox." Journal of Consumer Research 39 (3):445-460. https://doi.org/10.1086/664497

Ernest Baskin is an assistant professor of food marketing at the Erivan K. Haub School of Business at Saint Joseph's University. His research focus on consumer judgment and decision making with a particular interest in consumer biases and consumption decisions. His work on gift giving has appeared in the Journal of Consumer Research as well as multiple popular outlets such as the Chicago Tribune, NPR, Lifehacker, Nerdwallet and others. He holds a Bachelors of Science in Economics and a Bachelor of Arts in Anthropology from the University of Pennsylvania and a Ph.D. in Marketing from the Yale School of Management. 